\title{
A Low Cost Antibody Signal Enhancer Improves Immunolabeling in Cell Culture, Primate Brain and Human Cancer Biopsy
}

Catalina Flores-Maldonado, M. Estela Albino-Sanchez, Juan D. Rodriguez-Callejas, Argel Estrada-Mondragon, Ismael Leon-Galicia, Raul Maqueda-Alfaro, Claudia Perez-Cruz, Eberhard Fuchs, Alejandro Garcia-Carranca, Ruben G. Contreras, Fanis Missirlis and Abraham Rosas-Arellano

The self-archived postprint version of this journal article is available at Linköping University Institutional Repository (DiVA):

http://urn.kb.se/resolve?urn=urn:nbn:se:liu:diva-167640

N.B.: When citing this work, cite the original publication.

Flores-Maldonado, C., Estela Albino-Sanchez, M., Rodriguez-Callejas, J. D., Estrada-Mondragon, A., Leon-Galicia, I., Maqueda-Alfaro, R., Perez-Cruz, C., Fuchs, E., Garcia-Carranca, A., Contreras, R. G., Missirlis, F., Rosas-Arellano, A., (2020), A Low Cost Antibody Signal Enhancer Improves

Immunolabeling in Cell Culture, Primate Brain and Human Cancer Biopsy, Neuroscience, 439, 275286. https://doi.org/10.1016/j.neuroscience.2020.01.009

Original publication available at:

https://doi.org/10.1016/j.neuroscience.2020.01.009

Copyright: Elsevier

http://www.elsevier.com/

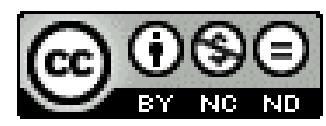




\section{Journal Pre-proofs}

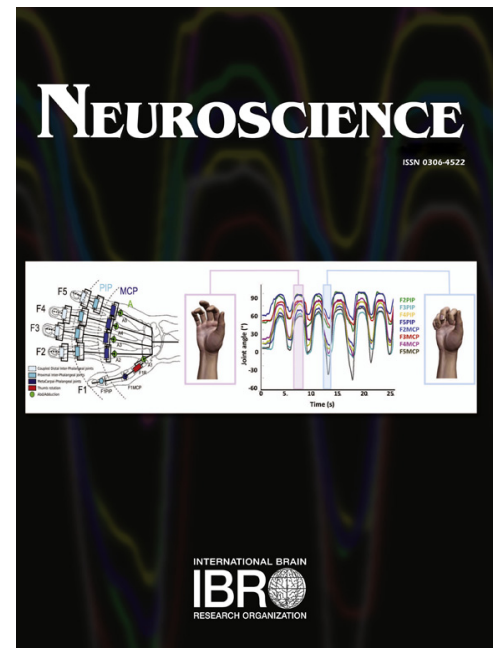

Research Article

A low cost antibody signal enhancer improves immunolabeling in cell culture, primate brain and human cancer biopsy

Catalina Flores-Maldonado, M. Estela Albino-Sánchez, Juan D. RodríguezCallejas, Argel Estrada-Mondragon, Ismael León-Galicia, Raúl MaquedaAlfaro, Claudia Perez-Cruz, Eberhard Fuchs, Alejandro García-Carrancá, Rubén G. Contreras, Fanis Missirlis, Abraham Rosas-Arellano

PII: $\quad$ S0306-4522(20)30022-1

DOI: $\quad$ https://doi.org/10.1016/j.neuroscience.2020.01.009

Reference: $\quad$ NSC 19468

To appear in: $\quad$ Neuroscience

Received Date: 28 March 2019

Revised Date: $\quad 2$ January 2020

Accepted Date: 6 January 2020

Please cite this article as: C. Flores-Maldonado, M.E. Albino-Sánchez, J.D. Rodríguez-Callejas, A. EstradaMondragon, I. León-Galicia, R. Maqueda-Alfaro, C. Perez-Cruz, E. Fuchs, A. García-Carrancá, R.G. Contreras, F. Missirlis, A. Rosas-Arellano, A low cost antibody signal enhancer improves immunolabeling in cell culture, primate brain and human cancer biopsy, Neuroscience (2020), doi: https://doi.org/10.1016/j.neuroscience.2020.01.009

This is a PDF file of an article that has undergone enhancements after acceptance, such as the addition of a cover page and metadata, and formatting for readability, but it is not yet the definitive version of record. This version will undergo additional copyediting, typesetting and review before it is published in its final form, but we are providing this version to give early visibility of the article. Please note that, during the production process, errors may be discovered which could affect the content, and all legal disclaimers that apply to the journal pertain.

(c) 2020 IBRO. Published by Elsevier Ltd. All rights reserved. 


\section{Running title}

A low cost antibody signal enhancer improves immunolabeling in cell culture, primate brain and human cancer biopsy

\section{Authors}

Catalina Flores-Maldonado ${ }^{1 \ddagger}$, M. Estela Albino-Sánchez ${ }^{2 \ddagger}$, Juan D. Rodríguez-Callejas ${ }^{3 \ddagger}$, Argel Estrada-Mondragon ${ }^{4}$, Ismael León-Galicia ${ }^{5}$, Raúl Maqueda-Alfaro², Claudia Perez-Cruz ${ }^{3}$, Eberhard Fuchs ${ }^{6}$, Alejandro García-Carrancá ${ }^{5}$, Rubén G. Contreras ${ }^{1}$, Fanis Missirlis $^{1}$, Abraham Rosas-Arellano ${ }^{7 *}$

\section{Affiliations}

${ }^{1}$ Departamento de Fisiología, Biofísica y Neurociencias, Centro de Investigación y de Estudios Avanzados del IPN, Zacatenco, Ciudad de México, México.

2 Departamento de Biología Celular, Centro de Investigación y de Estudios Avanzados del IPN, Zacatenco, Ciudad de México, México.

${ }^{3}$ Departamento de Farmacología, Centro de Investigación y de Estudios Avanzados del IPN, Zacatenco, Ciudad de México, México.

${ }^{4}$ Department of Clinical and Experimental Medicine, Linköping University, Linköping, Sweden.

5 Unidad de Investigación Biomédica en Cáncer, Laboratorio de Virus y Cáncer. Departamento de Biología Molecular y Biotecnología. Instituto de Investigaciones Biomédicas, Universidad Nacional Autónoma de México \& Departamento de Investigación Básica, Instituto Nacional de Cancerología (INCan), Secretaría de Salud. ${ }^{6}$ German Primate Center, Leibniz Institute for Primate Research, Göttingen, Germany. 7 Unidad de Imagenología, Instituto de Fisiología Celular, Universidad Nacional Autónoma de México, Ciudad de México, México.

$\ddagger$ These authors contributed equally to this work 
*Correspondence: Abraham Rosas-Arellano, arosasar@ifc.unam.mx or rosas.arellano@gmail.com. Unidad de Imagenología. Instituto de Fisiología Celular, Universidad Nacional Autónoma de México, Apartado Postal 70-242, Ciudad de México, 04510, México. Tel.: +52-555-622-5610

\section{Abstract}

The use of antibodies to identify neuronal receptors, neurotransmitters, cytoskeletal elements or pathologic protein aggregates, ion channels, adhesion molecules or other cell-type specific markers, is common practice in neuroscience. Antibody detection systems are often based on confocal, epifluorescence or brightfield microscopy. Three types of technical issues can interfere with immunolabeling: low abundance of the target protein, low specific affinity of the antibody and/or signal background sometimes related to tissue fixation. Here, giving tribute to Professor Miledi's mentorship, we propose the application of an antibody signal enhancer (ASE) solution based on glycine, hydrogen peroxide and a detergent mix as a simple, low cost, protocol variation that significantly and specifically improves the signal to noise ratio during immunostaining experiments. We describe three new settings in which ASE improves the detection of a variety of antibodies applied on long-time stored nonhuman primate brain sections, cell culture monolayers and on squamous carcinomas retrieved from cervical cancer patients. The significant improvement of ASE over optimized immunohistochemical protocols used in clinical practice (i.e. cancer detection) combined with its simplicity and low cost makes it an attractive method for biomedical applications.

\section{Keywords}

Astrocytes, claudins, early diagnosis, EGF, GFAP, human cervix, Ki67, Lgr5, biomedical application, Sox2

"If I have seen further, it is by standing on the shoulders of giants." 


\section{Introduction}

Professor Ricardo Miledi made numerous contributions to the development of neuroscience. Using the squid giant synapse he demonstrated the requirement of calcium in chemical synaptic transmission (Heuser and Miledi, 1970; Miledi, 1967; Miledi, 1969; Miledi and Slater, 1966). The large axonal diameter provided a specific advantage for amplifying electrical signals, thus improving their recording. He then implemented the now classic electrophysiology technique "Two Electrode Voltage Clamp" (TEVC) in Xenopus laevis oocytes injected with exogenous mRNA, coding for nicotinic acetylcholine receptors (Barnard et al., 1982). The finest details of heterologously expressed ion channels or neuronal receptors can be studied by this methodology (Bossi et al., 2007; Stuhmer, 1992). Faced with the disturbingly low signal-to-noise ratio recorded from nerve cells, Miledi's scientific approaches consisted of isolating the selective signal of the desired ion channel currents, which could then be amplified and further analyzed (Stuhmer, 1992). Faced with the difficulty of detecting genes or proteins that were expressed at low levels within small nuclei of the rodent brain, he suggested the alternative of using the large equivalent areas available in bovine brain, resulting in sufficient amounts of tissue for analysis by means of RT-PCR and immunohistochemistry assays (Lopez-Chavez et al., 2005; Rosas-Arellano et al., 2007). Known for his ingenuity and an incredibly voracious natural curiosity, Miledi chose to work on problems never tackled before by anyone else in basic and applied sciences, doing cutting edge work (Palma et al., 2011).

Selective signal amplification is still a common problem in many fields of science. Learning from Miledi's approach, we recently developed a simple solution for antibody signal enhancement (ASE) for use in immunostaining techniques (RosasArellano et al., 2016). ASE helps to identify the expression and location of proteins within cells or tissues (Bradbury and Pluckthun, 2015) addressing serious limitations due to the lack of an effective, reliable and accessible signal produced by antibody labeling (Schonbrunn, 2014). 
To prevent confusion with the terminology describing the variety of immunolabeling methods used in this study, we start with a brief presentation of the key terms: Immunohistochemistry refers to techniques in which monoclonal and/or polyclonal antibodies are used for determine distribution of specific antigens of interest over thin sections that are obtained from tissue samples (Rosas-Arellano et al., 2007). Immunocytochemistry refers to assays performed to search antigens over cells derived from cell culture, disintegrated tissues or smear samples (Sawa et al., 2017). The ending "chemistry" refers to immunostaining enzyme-mediated methods (immunohistoenzymes; (Streefkerk et al., 1975)). Fluorescent probes can also be used, in which case the techniques are referred to as immunofluorescence or immunohistofluorescence (Astruc et al., 2012) and immunocytofluorescence (Li et al., 2018), respectively. Variants of immunolocalization techniques can be direct or indirect. In the former condition primary antibodies are directly conjugated to a label; whereas in the latter, most widely used method, primary antibodies need to be recognized by the joining of tagged secondary antibodies (Hoffman et al., 2016). Compromises may occur in two general steps: (1) slide preparation, fixation, sample processing, antigen retrieval, non-specific site block, antigen recognition and tissues or cells mounting; (2) interpretation and quantification of results (Matos et al., 2010).

Common technical problems in immunostaining protocols relate to poor signal-tonoise ratios, either due to high background (autofluorescence or unspecific activity in enzyme-based detection systems), or due to aldehyde reactivity of the chemical fixation of the specimens (Rosas-Arellano et al., 2016; Taatjes and Roth, 2017). Accordingly, there has been sustained interest in improving immunolabeling protocols at every step, namely sample fixation, membrane permeabilization, antibody incubation and detection (Bondza-Kibangou et al., 2001; Gosselin et al., 1986; Hagedorn et al., 2006; Huang et al., 1976; Imam et al., 1995; Rosas-Arellano et al., 2018; Schnell et al., 1999; Shi et al., 1991; Waldvogel et al., 2006). Companies have developed signal enhancer kits; however, those are expensive and not affordable for many biomedical labs along the world. 
We developed a low-cost and efficient ASE, which is applied during blocking and with the primary antibody solution (Rosas-Arellano et al., 2016). This new ASE contains glycine, which competes with free aldehydes preventing their binding to the antibody and its epitopes; hydrogen peroxide, that quenches autofluorescence; and a mixture of Triton X-100 and Tween-20, that are non-ionic detergents displaying synergistic membrane permeabilization. Using a combination of these components results in significant improvement in signal-to-noise ratio in immunohistofluorescence and triple immunogold electron microscopy of rodent brain tissue (Rosas-Arellano et al., 2016). In this study, we aim to demonstrate the effectiveness of ASE by using of different antibodies and in a variety of tissues and cells. Moreover, we proved its potential use in human samples demonstrating its broader applicability for biomedical research and clinical practice. 


\section{Materials and Methods}

\section{Immunohistofluorescence protocols}

Animals. Laboratory-bred common marmosets (Callithrix jacchus, Order Primates) and tree shrews (Tupaia belangeri, Order Scandentia) were housed at the German Primate Center, Göttingen, Germany, under standard conditions complying with the European Union guidelines for the accommodation and care of animals used for experimental and other scientific purposes (2007/526/EC). All experiments were performed in accordance with the European Communities Council Directive 86/609/EEC and the German legislation on animal rights and welfare. Experienced veterinarians and caretakers constantly monitored the animals. Animals did not present neurological disorders or other injuries that can cause trauma to the central nervous system.

Tissue preparation. Three brains of old male marmosets (mean age 11 years old) and three brains of old male tree shrews (mean age 6.3 years old) were used. All animals were anesthetized with GM II (ketamine (Ketavet1, Pharmacia \& Upjohn, Erlangen, Germany), xylazine (Rompun®, Bayer, Leverkusen, Germany) and atropine (WDT, Hannover, Germany) 5:1:0.01, (Rensing S, 1999)) and received, after loss of consciousness, an intraperitoneal injection of ketamine (400 mg/kg body weight) before sacrifice. Bodies were transcardially perfused with $4^{\circ} \mathrm{C} 0.9 \% \mathrm{NaCl}$ saline for 5 min. Subsequently, $4^{\circ} \mathrm{C} 4 \%$ paraformaldehyde (PFA) in $0.1 \mathrm{M}$ phosphate buffer, $\mathrm{pH}$ 7.2, was infused for $15 \mathrm{~min}$ to fix the brain tissue. The brains were removed, postfixed and stored in fresh $4 \% \mathrm{PFA}$ at $4{ }^{\circ} \mathrm{C}$. Upon receipt in the laboratory, the tissue was thoroughly washed with $0.1 \mathrm{M}$ phosphate buffered saline (PBS) $0.14 \mathrm{M} \mathrm{NaCl}, 2.95$ $\mathrm{mM} \mathrm{KCl}, 8.09 \mathrm{mM} \mathrm{Na}_{2} \mathrm{HPO}_{4}, 1.47 \mathrm{mM} \mathrm{KH}_{2} \mathrm{PO}_{4}$; pH 7.4. Four days before sectioning, the tissue was immersed in $30 \%$ sucrose in PBS and kept at $4{ }^{\circ} \mathrm{C}$. Coronal sections of the common marmoset brains $(40 \mu \mathrm{m})$ were obtained from the hippocampal formation (Bregma $8.00 \mathrm{~mm}$ to $0.80 \mathrm{~mm}$ according to Paxinos (Franklin KBJ and Paxinos G, 2013)). Axial sections of the tree shrew brains $(40 \mu \mathrm{m})$ were obtained from hippocampal formation according to (Keuker JI et al., 2003). The sections were 
obtained using a sliding microtome (Leica RM2235). All sections were immediately immersed in cryo-protective solution: $300 \mathrm{~g}$ sucrose; $10 \mathrm{~g}$ polyvinyl-pyrrolidone [PVP-40, Sigma]; $500 \mathrm{~mL}$ of $0.1 \mathrm{M} \mathrm{PB}$ and $300 \mathrm{~mL}$ ethylene glycol, for $1 \mathrm{~L}$, and stored at $-20^{\circ} \mathrm{C}$ until use.

Standard immunohistofluorescence protocol (SIP). SIP was used as previously described (Rodriguez-Callejas et al., 2016). Sections were permeabilized with $0.2 \%$ Triton X-100 in PBS (T-PBS) during 20 min. Thereafter, sections were treated with 0.1 $\%$ BSA for $30 \mathrm{~min}$, washed three times with T-PBS and incubated overnight at $4{ }^{\circ} \mathrm{C}$ with the primary antibody anti-Glial fibrillary acidic protein (GFAP) (goat, IgG, Abcam, Cat. No. Ab53554, 1:300). The sections were washed three times with T-PBS and incubated two hours at room temperature (RT) with the secondary antibody Alexa Fluor 647 (anti-goat IgG, Jackson Immuno Research, Cat. No. 705-605-147, 1:500) diluted in T-PBS. The sections were washed three times with T-PBS and incubated during 30 min with DAPI (4'-6-diamidino-2-phenylindole; Invitrogen, 1:1 000) in TPBS, washed again, mounted on glass slides and cover slipped with mounting medium VectaShield (Vector Laboratories). Notice that glycine treatment was not include in SIP.

Immunohistofluorescence using ASE. The ASE protocol has been described in detail previously (Rosas-Arellano et al., 2016). Briefly, brain sections were rinsed with $0.5 \%$ Tween20 in PBS twice for 3 min and incubated for 30 min in ASE blocking solution containing $50 \mathrm{mM}$ glycine, $0.1 \%$ TritonX-100, $0.1 \%$ BSA, $0.05 \%$ Tween20 and $2 \%$ donkey serum (serum should be of the host species from where the secondary antibody was raised) in PBS. The primary antibody anti-GFAP (goat, IgG, Abcam, Cat. No. Ab53554, 1:300) was diluted in the ASE primary antibody solution, which contains $0.1 \%$ TritonX-100, $0.05 \%$ Tween $20,0.1 \%$ hydrogen peroxide and $10 \mathrm{mM}$ glycine in PBS and applied to the sections overnight at $4^{\circ} \mathrm{C}$. On the following day, the sections were washed three times with $0.5 \%$ PBS-Tween 20 for 5 min and incubated for $2 \mathrm{~h}$ at RT with the secondary antibody Alexa Fluor 647 (donkey anti-goat IgG, Jackson Immuno Research, Cat. No. 705-605-147, 1:500) diluted in $0.1 \%$ Tween20 in 
PBS. Sections were washed three times with $0.5 \%$ Tween20 in PBS and incubated during 30 min with DAPI (4'-6-diamidino-2-phenylindole; Invitrogen, 1:1 000) in 0.5 \% Tween20 in PBS. The sections were then washed, mounted on glass slides and cover slipped with mounting medium VectaShield.

Multiple labeling of immunohistofluorescence combining SIP and ASE. Selective immunosignal amplification for GFAP signal was obtained using the ASE protocol in a triple-immunohistofluorescence protocol. The sections were incubated with ASE blocking solution as described above for $30 \mathrm{~min}$. The primary antibody anti-GFAP (goat, IgG, Abcam, Cat. No. Ab53554, 1:300) was incubated overnight at $4^{\circ} \mathrm{C}$ in ASE primary antibody solution. The sections were rinsed three times with $0.5 \%$ Tween20 in PBS for $5 \mathrm{~min}$ and incubated with the first secondary antibody Alexa Fluor 647 (donkey anti-goat IgG, Jackson Immuno Research, Cat. No. 705-605-147, 1:500) diluted in $0.1 \%$ Tween 20 solution for $2 \mathrm{~h}$ at RT. The sections were rinsed three times with $0.5 \%$ Tween20 in PBS for 5 min. For second primary antibody, AT100, the SIP protocol was used. Sections were treated with T-PBS during $20 \mathrm{~min}$ and then incubated overnight at $4^{\circ} \mathrm{C}$ with the second primary antibody AT100 (mouse, IgG, Thermo Scientific, Cat. No. MN1060, 1:500). Sections were washed three times (10 min each) with T-PBS and incubated with the second secondary antibody Alexa Fluor 488 (donkey anti-mouse IgG, Jackson Immuno Research, Cat. No. 715-545-150, 1:500) diluted in T-PBS, 2 hours at RT. The sections were rinsed three times (10 min) with TPBS. The SIP protocol was also used for the third primary antibody anti-ferritin (rabbit anti-horse, IgG, Sigma-Aldrich, Cat. No. F6136, 1:1000). The primary antiferritin and its corresponding secondary antibody incubation and washes were performed as mentioned before. The third secondary antibody was Cy3 (donkey antirabbit IgG, Jackson Immuno Research, Cat. No. 711-165-152, 1:500). Sections were washed three times (10 min each) with T-PBS and incubated during 30 min with DAPI (1:1000) in T-PBS. The sections were then washed once again (see above), mounted on glass slides and cover slipped with mounting medium VectaShield.

\section{Immunocytofluorescence protocol}


Cell line. Epithelial Madin-Darby canine kidney cell line (MDCK) was purchased from ATCC@ (CRL-2936TM). After culturing, the cells were cloned. In this work, clone 7.11 was used for its epithelial phenotype: the compact polygonal cells develop in a monolayer, their cell membrane shows asymmetric protein distribution as well as the typical union complex that binds the cells together (Cereijido et al., 1978). MDCK cells make tight junctions between them, whose sealing is directly proportional to the electrical resistance of the monolayer to the passage of current.

Cell culture. Cells were maintained in cell culture dishes (430167, Corning®, Corning, $\mathrm{NY}$ ) at $37^{\circ} \mathrm{C}$ in an incubator containing $5 \% \mathrm{CO}_{2}$ (MCO-5AC Sanyo Electronic Co. Ltd., Japan) in Dulbecco's modified Eagle's medium (DMEM; 31600-083, Life Technologies, Carlsbad, CA) enriched with $10 \%$ bovine serum (10371-029, Life Technologies) and $100 \mathrm{U} / \mathrm{ml}$ of penicillin and streptomycin (A-01, In Vitro, CDMX, Mexico) named CDMEM. For experiments, the cell monolayers were washed three times with PBS (003000, GIBCO) without calcium, incubated in PBS without calcium during 20 min under incubator atmospheric conditions. To induce cell-cell and cell-substrate detachment, the culture was incubated with trypsin-versene solution (EN-005 In Vitro, CDMX, Mexico) during 15 min. The cell suspension was recovered with CDMEM and seeded at a density of $2.25 \times 10^{5}$ cells $/ \mathrm{cm}^{2}$ onto polycarbonate Transwells ${ }^{\circledR}$ inserts (3415 Corning Costar, Cambridge, MA) and cultured during 55 h in 24 multichamber wells. The cultures were transferred to a DMEM without serum for further $24 \mathrm{~h}$ and then to DMEM containing $100 \mathrm{ng} / \mathrm{ml}$ EGF (AF-100-15, Peprotech, NJ) during $15 \mathrm{~h}$. The control condition was in absence of EGF.

Immunocytofluorescence using BSA or ASE protocols. After 15h in EGF culture, the cell monolayers were washed with PBS, fixed and permeabilized with methanol during 10 min at $-20^{\circ} \mathrm{C}$ and rehydrated in PBS during $10 \mathrm{~min}$ at RT. The cell monolayers were processed for immunocytofluorescence either using the BSA solution for antibody incubation or using the ASE protocol. Non-specific binding was blocked by incubating during 30 min in $3 \%$ BSA in PBS or in ASE blocking solution (here $50 \mathrm{mM}$ glycine, 0.05 
\% Tween 20, $0.1 \%$ Triton X-100 and $0.1 \%$ BSA and FBS $2 \%$ instead of donkey serum) in PBS. Then, the primary antibodies anti-Claudin-2 (rabbit anti cldn2 IgG, Invitrogen Cat. No. 516100, 1:1000) and anti-Claudin-4 (mouse anti cldn4 IgG1, Invitrogen Cat. No. 329400, 1:1000) diluted in 3 \% BSA-PBS (control) or in ASE solution, were applied to the cell monolayers for $1 \mathrm{~h}$ at RT. Three washes with PBS, followed by a 30 min incubation with the secondary antibodies (Alexa Fluor 555 goat anti-rabbit and FITC goat anti-mouse, Life Technologies, Eugene, both 1:100) diluted in 0.1 \% Tween 20 in PBS and further three washes with PBS and two with deionized water. The culture supports were then cut away from the frames and mounted with Vectashield mounting medium. Notice that glycine treatment was not including BSA.

\section{Immunohistochemistry protocol}

Tissue acquisition. Cervical tissues were obtained from archival material in the Pathology Division of the Instituto Nacional de Cancerología (INCan), Mexico City. Three squamous cell carcinomas from biopsies or excisions of three patients in the pathology archive were reviewed by pathology and classified.

Tissue preparation for immunohistochemistry. Three-micron-thick sections were deparaffinized and rehydrated followed by antigen retrieval using ImmunoDNA Retriever 20X (Cat. No. BSB 0023) with citrate, heat at $95^{\circ} \mathrm{C}$ for $15 \mathrm{~min}$. The sections were incubated with PolyDetector Peroxidase Blocker (Cat. No. BSB 0050) to block endogenous peroxidase activity for $40 \mathrm{~min}$ at RT, and then with ImmunoDetector Protein Blocker / Antibody Diluent Bio SB (BSB 0040) 30min at RT. Anti-Ki67 (rabbit anti-Ki67, IgG, Abcam Cat. No. ab16667, 1:200), anti-Sox-2 (mouse anti Sox-2, IgG2a Santa Cruz Biotechnology, Cat. No. sc-365964, 1:50), anti-Lgr5 (rabbit anti-GPCR GPR43, IgG Abcam Cat. No. ab118449, 1:50) were incubated separately at $4^{\circ} \mathrm{C}$ overnight. The slides were washed 3 times for 5 min each with $0.1 \%$ Tween 20 in PBS and incubated with anti-rabbit HRP polymer (MACH 3 Rabbit HRP Polymer Detection Cat. No. M3R531 Biocare) for $30 \mathrm{~min}$ at RT or Mouse/Rabbit ImmunoDetector DAB HRP Brown Detection System (Cat. No. BSB 0001) for $40 \mathrm{~min}$ at RT. Samples were 
washed thrice for 5 min each with PBS-0.1\% Tween 20 and then counterstained with hematoxylin (Cat. No. 738, HYCEL) and dehydrated before mounting the slides with permount. For a comparison between the reagents applied in the conventional immunostaining protocol and the ASE procedure see table 1. Only the primary antibody incubation solution and protein blocker were modified from the protocol mentioned above. Non-specific sites were blocked by incubating for 30 min with an ASE blocking solution containing $2 \%$ fetal bovine serum, $50 \mathrm{mM}$ glycine, $0.05 \%$ Tween20, $0.1 \%$ Triton X-100 and $0.1 \%$ BSA diluted in PBS. The slides were then incubated separately with the primary antibodies diluted in ASE incubation solution at $4^{\circ} \mathrm{C}$, overnight. The rest of the protocol was identical.

\section{Image acquisition}

A confocal laser scanning microscope (Leica TCS-SP8) equipped with Diode (405nm), OPSL (488 nm), OPLS (552 nm), and Diode (638 nm) laser was used. Marmoset brain sections were imaged by use of both lasers with 700 gain, -0.4 offset and $1.0 \mathrm{UA}$ pinhole diameter. For Tree shrew brain sections under conventional SIP protocol the parameters were 700 gain, -1.0 offset and 1.0 UA pinhole diameter for ASE-treated samples; however in sections treated with ASE the parameters were adjusted to 600 gain, -1.0 offset and 1.0 UA pinhole diameter, due to improved immunodetection of GFAP positive signal in ASE treated slices. Confocal images were obtained as Z-stacks of single optical sections. In the case of marmoset, we obtained images of $22 \mu \mathrm{m}$ with 34 Z-stacks. For tree shrew, we obtained images of $11.56 \mu \mathrm{m}$ with $18 \mathrm{Z}$-stacks. Stacks of optical sections were superimposed as a single 2D image using the Leica LAS X software. For MDCK cell line images lasers were always used with 740 gain, -0.48 offset and 1.0 UA pinhole diameter for Claudin 2 and 4 assays and 581 gain, 1.10 offset, $1.0 \mathrm{UA}$ pinhole diameter (555), and 800 gain, 0.0 offset and 1.0 UA pinhole diameter for EGF assays. For cancer cervical tissues photomicrographs were obtained using a transmitted and reflected light Olympus BX51TRF stage model U-SVRB-4 microscope, equipped with Olympus DP72 digital and color camera and pixelink software. 


\section{Statistical analysis}

Three slices from marmoset and three from tree shrews' brains were imaged. From each slice we obtained three images from the dentate gyrus-CA3 hippocampus region. For immunocytochemistry, three cell monolayers for Cldn-2 and another three for Cldn-4 were used for each condition of the EGF experiments. For analysis of cervical cancer samples, three images per patient sample for each treatment were analyzed. In all cases, the Image software from $\mathrm{NIH}$ was used to analyze the population (immunohistofluorescence) or signal intensity (immunohisto-, immunocytofluorescence and immunohistochemistry) on each photomicrograph. Functions "pluging" - "analyze" - "cell counter" were used to quantify the total number of astrocytes. The "free hand" function was used to outline astrocytic processes, defined as GFAP-positive segments longer than $4 \mu \mathrm{m}$. The "free hand" function was also use to outline the MDCK membranes and the positive cancer cells. The region of interest (ROI) for each microphotograph were selected when their signal was clearly detected, i.e. astrocyte processes derived from a concentric point where DAPI was present, cell membrane for MDCK cells and in invert images clear signals for cancerous samples. The background signal was subtracted from the positive signal thus obtaining the relative intensity of the signal for each antibody. For signal intensity 8-bit images were used between 1200-1600 \% of magnification permitting the clear delineation of each ROI in all experiments. Signal intensity was measured using the functions "analyze" - "tools" - "ROI manager". For astrocytes in non-human primates the outline function was also used to quantify astrocytic processes, defined as GFAP-positive segments longer than $4 \mu \mathrm{m}$. This was realized using "pluging" - "analyze" - "cell counter" functions. Statistical analyses were performed using the unpaired Student's t test. Differences between groups were considered statistically significant when $\mathrm{p} \leq 0.05$. Data are presented as means \pm S.D. (Fogerson et al., 2016; Rosas-Arellano et al., 2016). 


\section{Results}

\section{Single immunohistofluorescence and triple labeling using a combined SIP and ASE protocol in brain sections}

Application of the ASE protocol on rodent brain tissue revealed that GFAP-positive cells display long, slender and smooth processes with few or no branches, sometimes with end feet surrounding cerebral capillaries (Rosas-Arellano et al., 2016). This characteristic morphology of astrocytes makes their identification by immunofluorescence straightforward, however the SIP results in a weak specific signal for GFAP. We questioned whether the SIP and ASE protocols could be combined but applying ASE selectively to increase the immunodetection of GFAP in brain slices of two different animal species: a non-human primate, the common marmoset, and a Scandentia order tree shrew.

A prominent presence of astrocytes has been previously detected in the dentate gyrus-CA3 hippocampal region of rodents (Kim et al., 2018) and marmosets (Rodriguez-Callejas et al., 2019). Application of the ASE solution increased the fluorescence intensity compared to the SIP protocol. As a consequence, the number of GFAP-positive astrocytes detected in brain slices of both animal species increased (compared ASE vs SIP in Figure 1A and 1B). The enhanced GFAP fluorescence intensity under ASE is shown on the right in Figure 1C. We also applied the ASE with anti-GFAP in a triple labeling protocol where anti-ferritin and AT100 were processed with SIP (Figure 1D). A representative photomicrograph of this triple immunofluorescence labeling shows that all three antibodies display selective discrimination for an epitope, as immunolabeling was detected in different cell types. Ferritin immunoreactivity was present in microglia (Rodriguez-Callejas et al., 2019), AT100 in neurons from the stratum pyramidale (Chatterjee et al., 2018) and GFAP in astrocytes (Rodriguez-Callejas et al., 2019). This experiment demonstrated that ASE 
can be used with only one antibody, without affecting the results from established antibodies that work well with the normal SIP protocol.

\section{Improved demonstration of the differential response of the epithelial tight junction claudins to epidermal growth factor (EGF) treatment in cell monolayer cultures}

EGF is a key regulator of epithelial paracellular permeability, a property that depends on the downregulation of tight junction proteins Claudin-2 and upregulation of Claudin-4 through ERK1/2, Src and STAT3 (Garcia-Hernandez et al., 2015). Regulation of paracellular permeability is a key factor in the immune-barrier function of epithelia, for example against pathogenic amoebae (Flores-Maldonado et al., 2017) or the dengue virus (Idris et al., 2019). Immunocytofluorescence in MDCK monolayer cells using Claudin 2 and Claudin 4 antibodies has previously revealed their localization in both the plasma membrane and in subcellular membrane organelles, although the antibody signal is not always easy to detect, especially in the case of Claudin 4. As ASE is an effective immunosignal enhancer and its application apparently does not produce artefacts in the location of the immunolabels, we decided to use ASE to observe the effect of EGF treatment on Claudin 2 and 4, whose expression in MDCK cells is EGF sensitive in a differential way: the Claudin 2 signal decreases while the Claudin 4 signal increases (Flores-Benitez et al., 2007; Garcia-Hernandez et al., 2015). First, we compared the standard BSA method to the application of the ASE treatment (Figure 2A). The latter improved considerably the distinctive Claudin 4 honeycomb pattern stain using an antibody dilution of 1:1000 (a 10-fold improvement from the previously published protocol). Quantification of the data showed significant increases in the fluorescence intensity and the immunolabel signal distribution over the cell membrane area. Application of ASE in the EGF-treated monoculture demonstrated beautifully the known differential response of Claudin 2 and Claudin 4, providing clear images and a quantifiable response (Figure 2B). Thus, with these experiments, we extend the recommended use of ASE for fluorescent antibody 
staining protocols applied to cell culture and for the detection of membrane-bound proteins.

\section{ASE increases the signal intensity of different antibodies in cancer patient biopsies}

Immunohistochemistry is increasing being applied in clinical practice for more accurate and precise diagnosis and prognosis in the management of tumors (Kalebi and Dada, 2007). Tumor classification is based on semi-quantitative analysis of different biomarkers following immunohistochemical assays (McCluggage, 2007). Cervical cancer in particular affects 500,000 individuals each year, primarily in the developing countries (Organization WH, 2018). Cervical cancer is the main cause of death from cancer in the female Mexican population with a mortality rate of 6 deaths per 100,000 women (National epidemiological surveillance system. Unique information system. Ministry of Health M, 2018). The cellular dysregulation associated with cancer is evidenced clinically by immunohistochemical studies of protein markers, such as Ki67, Sox2 and Lgr-5. Because Ki67 is a nuclear protein expressed exclusively in mitotically active cells, but not during cell cycle arrest, detection of Ki67 in biopsies correlates with high cellular proliferation and is therefore associated with cancer disease (Brown et al., 2012; Evanthia and Georgios, 2012). Given the critical role of cancer stem cells in tumorigenicity and metastasis (Reya et al., 2001), the expression of the stem cell marker Sox2 is crucial for progression of human cervical squamous cell carcinoma (Ji et al., 2014). Another marker of adult stem cells is Lgr5, a membrane G-protein coupled receptor (Hsu et al., 1998). Lgr5 upregulation was proposed as an early diagnostic and prognostic biomarker (Zheng et al., 2013), its expression was significantly higher in cervical cancer tissues compared with adjacent normal cervix and correlated positively with tumor size (Sun., 2015).

Given the simple nature of ASE and to the high selectivity in removing signal to noise ratio, we explored its applicability as a reagent in clinical procedures, comparing its 
application over standard protocols for human carcinoma samples (Lopez et al., 2012). Cervical squamous cell carcinoma is a major cause of cancer-related mortality globally (Shimada et al., 2013). Immunohistochemical studies of the cell proliferation marker Ki67 and the stem cell markers Sox-2 (nuclear) and Lgr5 (membranous) are used clinically for cancer prognosis of the squamous carcinoma (Chen et al., 2014; Kanthiya et al., 2016; Martinez-Ramirez et al., 2017). Using malignant tissue from three patients, the classic immunolocalization protocol was evaluated under similar working conditions vs the ASE method. Application of the ASE produced a 1.7-fold increase in the intensity of the Ki67 signal against the control, a 1.5-fold increase for Sox2 and 1.7-fold increase for Lgr5, respectively (Figure 3). Thus, the higher sensitivity provided by the application of the ASE offers a low cost improvement of the immunohistochemically schemes currently used in the clinic for the detection of cancer. It was also important to demonstrate that ASE does not produce artifacts on its own; therefore control samples were processed in parallel using the same protocols (commercial diluent and ASE) but omitting the primary antibodies. As expected, no signal was detected (Figure 4A). Likewise, both the ChromPure rabbit IgG (011-000-003-Jackson) at 1:50 dilution and the ChromPure mouse IgG at 1:50 dilution (015-000-003- Jackson) isotype control were diluted in ASE and showed no signal (Figure 4B). Thus, the higher sensitivity provided by the application of the ASE (Figure 3) offers a low cost improvement of the immunohistochemically schemes currently used in the clinic for the detection of cancer.

\section{Discussion}

The findings described in this paper leave little scope for discussion: our readers using immunolabeling assays should consider the technical benefits of adding ASE to their blocking and primary antibody solutions. We show that ASE can be applied for antibodies that give weak signals and be omitted if antibodies work well. Furthermore, we found that ASE could still offer the convenience of reducing the amount of the antibody (by using less concentrated dilution), which can be important when the quantity of the available reagent is limiting. Another important advantage of 
ASE is the reduced autofluorescence. The chemical reasoning of why ASE reduces autofluorescence and improves signal specificity was presented before (RosasArellano et al., 2016). Three laboratories contributed the experiments for the present study working independently and showing clear replicability. ASE applicability can also be appreciated from other examples in the literature. Lamprey spinal cord cryosections were processed for triple immunofluorescence using ASE following repeated spinal transections to evaluate the resilience of its neuroregenerative capacity (Hanslik et al., 2019). Rodent brains were processed for triple immunogold electron microscopy using ASE, revealing a subcellular relocalization from the synapse periphery to within the synaptic cleft of GABA-A receptors during mutanthuntingtin evoked neurodegeneration (Rosas-Arellano et al., 2018). ASE was also key to visualize arginase, a protein below the SIP detection limit, expressed in a subset of marmoset microglia (Rodriguez-Callejas et al., 2019) and it was also applied to a murine in vitro blood-brain barrier model in order to visualize the changes in tight junctions that explain how dengue virus compromises its integrity (Idris et al., 2019). Last, but not least, ASE also competes favorably with commercially available antibody signal enhancers and discloses composition (Rosas-Arellano et al., 2016). ASE is an effective reagent that can be combined with other protocols and solutions in multiple labeling immunohistofluorescence increasing selective antibody signal, without causing alterations or interference between protocols or antibodies.

Immunohistochemistry was revolutionized by the development of enzyme-mediated methods (Sternberger and Sternberger, 1986). Immunohistochemistry commonly display weak signals due to use of fixative solutions that alter the native tertiary configuration of the proteins, producing autofluorescence, and protein cross-linking (Saper and Sawchenko, 2003). The masking epitopes and changes in protein structures subsequently alter the efficiency of antibodies to bind to their antigens (Libard et al., 2019). There have been numerous improvements aimed to avoid autofluorescence coming from many biomolecules of cells and tissues, which can be solved by the use of far-red fluorophores (Prieto et al., 2014) as well as to intensify histochemical reactions by removing aldehydes from epitopes, bleaching molecules, and increasing signals of low abundant antigen (Low et al., 2017). Different conditions 
of microwave irradiation power and time cycles, prolonged triton treatment, use of avidin-biotin and tyramide signal amplification (TSA) are examples for amplifying the signal of antibodies as well as the sensitivity of detection (Adams, 1992; Hsu et al., 1981; Shi et al., 1991; Zaglia et al., 2016). The use of avidin-biotin interaction in immunoenzymatic techniques, for instance, provides a simple and sensitive method to localize antigens with very high affinity. The most frequent example is a biotin linked primary antibody that binds to the peroxidase-bound streptavidin, which is able to amplify very weak signals (up to $100 \mathrm{x}$ more sensitive than the standard immunofluorescent techniques) (Hsu et al., 1981). Another immunoenzimatic technique widely used is the TSA, which is based on a catalytic reporter deposit adjacent to the epitope of interest (Adams, 1992). These techniques have shown enhanced sensitivity, specificity and compatibility with multi-label fluorescent microscopy and have been very extensively commercialized (Hoffman et al., 2016). Modifications to TSA have led to enhance immunocytochemical identification of the immediate early gene product cFos, using nickel-enhanced diaminobenzidine (DAB) as a chromogen for the reaction, improving both immunoperoxidase reaction and fluorescence detection (Berghorn et al., 1994). When employing strategies using enzymes to produce a coloured product, the choice of enzyme and substrate can significantly affect the sensitivity of the method. Peroxidase reactions of this type are thus self-limiting in terms of how much product can be generated, the substrate creates a peroxidase product that is not a precipitate, it will accumulate in the cell, and has the disadvantage that eventually can fade (Hoffman et al., 2008). In this regard the amplified fluorescence assay generates products which deposit biotin over the enzyme, and the biotin is then coupled to a streptavidin-linked fluorophore, being the fluorescence generated about two orders of magnitude greater than that obtained with the other fluorescent methods (Berghorn et al., 1994). In any case, for all these enzymatic methods it is fundamental to consider that the ability to detect a particular antigen will be a function of 1) how much antigen is present, 2) the affinity of the antibodies used to bind to the antigen, 3) how much accumulated product is deposited by the reaction, and 4) the strategy used for visualization (Hoffman et al., 2008). Finally but not of less importance, poor signal related to the inadequate 
immunolabeling procedures due to low quality of antibodies sometimes lies behind poor reproducibility of results, an increasingly common concern of the scientific community (Nosek and Errington, 2017; Voskuil, 2017). Factors as the thickness of the sample, different code number of antibody clones, bleedings from different days and/or immunized animals, absent of disclosure of the full sequence of immunizing peptide by the companies, nature of the antibody (polyclonal or monoclonal), contributes to the problem of reproducibility of published results (Libard et al., 2019; Saper and Sawchenko, 2003).

Here we emphasize that the main advantage of the ASE methodology lies in its simplicity and effectiveness; the method can easily be used as a low-cost first approach technique before the use of more expensive and lengthier procedures that require prior standardization. The ASE methodology is robust and reproducible. Our data also show a clear advantage of ASE in clinical practice. Early detection of cancer on biopsies saves lives: ASE can reduce false negative samples or autofluorescence artifacts. Here, as a modest tribute to Miledi's original spirit of adventure and innovation, we propose that low cost ASE as an improved method for immunolabeling detection in human cancer samples and in other challenging experimental settings. We call for further tests to establish whether ASE should be incorporated in clinical use.

\section{Declaration of Conflicting Interests}

The authors declared no potential conflicts of interest with respect to the research, authorship, and/or publication of this article.

\section{Acknowledgements}

Professor Ricardo Miledi worked at the bench in his laboratory at the University of California, Irvine until the end of his life. He understood the importance of doing science in Mexico and supported generously many scientists from his native land. He 
led a bi-national laboratory (UCI-UNAM campus Juriquilla) and playing a key role in the foundation of the Institute of Neurobiology of the National Autonomous University of Mexico, in Juriquilla, Queretaro, where one of his former students, Professor Ataúlfo Martínez-Torres, served as the Ph.D. mentor of AR-A and AE-M and where a six-month visit of FM (where he later became AR-A's postdoctoral mentor) in 2007 was the prelude to his eventual relocation to Mexico. AR-A acknowledges support from the Unidad de Imagenologia IFC-UNAM in the preparation of this manuscript. We would like to thank Leopoldo Flores Romo, Ph.D. and Juana Calderon Amado M.Sc. (CINVESTAV-Mexico) for excellent technical support. MEA-S, RM-A and JDR-C are supported with a fellowship from CONACYT-Mexico (Postdoctoral \#264069, PhD \#295473 and PhD \#308515, respectively). 


\section{References}

Adams JC (1992), Biotin amplification of biotin and horseradish peroxidase signals in histochemical stains. J Histochem Cytochem 40:1457-1463.

Astruc T, Peyrin F, Venien A, Labas R, Abrantes M, Dumas P, Jamme F (2012), In situ thermal denaturation of myofibre sub-type proteins studied by immunohistofluorescence and synchrotron radiation FT-IR microspectroscopy. Food Chem 134:1044-1051.

Barnard EA, Miledi R, Sumikawa K (1982), Translation of exogenous messenger RNA coding for nicotinic acetylcholine receptors produces functional receptors in Xenopus oocytes. Proc R Soc Lond B Biol Sci 215:241-246.

Berghorn KA, Bonnett JH, Hoffman GE (1994), cFos immunoreactivity is enhanced with biotin amplification. J Histochem Cytochem 42:1635-1642.

Bondza-Kibangou P, Millot C, Dufer J, Millot JM (2001), Microspectrofluorometry of autofluorescence emission from human leukemic living cells under oxidative stress. Biol Cell 93:273-280.

Bossi E, Fabbrini MS, Ceriotti A (2007), Exogenous protein expression in Xenopus oocytes: basic procedures. Methods Mol Biol 375:107-131.

Bradbury A, Pluckthun A (2015), Reproducibility: Standardize antibodies used in research. Nature 518:27-29.

Brown CA, Bogers J, Sahebali S, Depuydt CE, De Prins F, Malinowski DP (2012), Role of protein biomarkers in the detection of high-grade disease in cervical cancer screening programs. J Oncol 2012:289315.

Cereijido M, Robbins ES, Dolan WJ, Rotunno CA, Sabatini DD (1978), Polarized monolayers formed by epithelial cells on a permeable and translucent support. J Cell Biol 77:853-880.

Chatterjee S, Cassel R, Schneider-Anthony A, Merienne K, Cosquer B, Tzeplaeff L, Halder Sinha S, Kumar M, et al. (2018), Reinstating plasticity and memory in a tauopathy mouse model with an acetyltransferase activator. EMBO Mol Med 10.

Chen Q, Cao HZ, Zheng PS (2014), LGR5 promotes the proliferation and tumor formation of cervical cancer cells through the Wnt/beta-catenin signaling pathway. Oncotarget 5:9092-9105.

Evanthia A, Georgios K, Immunohistochemistry in the Diagnosis of Squamous Intraepithelial Lesions of the Uterine Cervix, in: Vanden Broeck D (Ed.) Human Papillomavirus and Related Diseases, From Bench to Bedside - A Clinical Perspective, InTech, 2012, pp. 41-64.

Flores-Benitez D, Ruiz-Cabrera A, Flores-Maldonado C, Shoshani L, Cereijido M, Contreras RG (2007), Control of tight junctional sealing: role of epidermal growth factor. Am J Physiol Renal Physiol 292:F828-836.

Flores-Maldonado C, Gonzalez-Robles A, Salazar-Villatoro L, Omana-Molina M, Gallardo JM, Gonzalez-Lazaro M, Hernandez-Ramirez VI, Talamas-Rohana P, et al. (2017), Acanthamoeba (T4) trophozoites cross the MDCK epithelium without cell damage but increase paracellular permeability and transepithelial resistance by modifying tight junction composition. Exp Parasitol 183:69-75. 
Fogerson SM, van Brummen AJ, Busch DJ, Allen SR, Roychaudhuri R, Banks SM, Klarner FG, Schrader T, et al. (2016), Reducing synuclein accumulation improves neuronal survival after spinal cord injury. Exp Neurol 278:105-115.

Franklin KBJ, Paxinos G (2013) Paxinos and Franklin's The mouse brain in stereotaxic coordinates. Amsterdam: Academic Press, an imprint of Elsevier.

Garcia-Hernandez V, Flores-Maldonado C, Rincon-Heredia R, Verdejo-Torres O, BonillaDelgado J, Meneses-Morales I, Gariglio P, Contreras RG (2015), EGF regulates claudin-2 and -4 expression through Src and STAT3 in MDCK cells. J Cell Physiol 230:105-115.

Gosselin EJ, Cate CC, Pettengill OS, Sorenson GD (1986), Immunocytochemistry: its evolution and criteria for its application in the study of epon-embedded cells and tissue. Am J Anat 175:135-160.

Hagedorn M, Neuhaus EM, Soldati T (2006), Optimized fixation and immunofluorescence staining methods for Dictyostelium cells. Methods Mol Biol 346:327-338.

Hanslik KL, Allen SR, Harkenrider TL, Fogerson SM, Guadarrama E, Morgan JR (2019), Regenerative capacity in the lamprey spinal cord is not altered after a repeated transection. PLoS One 14:e0204193.

Heuser J, Miledi R (1970), Autoradiography of labelled amino acids injected iontophoretically into the giant squid synapse. J Physiol 208:55P-57P.

Hoffman GE, Le WW, Sita LV (2008), The importance of titrating antibodies for immunocytochemical methods. Curr Protoc Neurosci Chapter 2:Unit 212.

Hoffman GE, Murphy KJ, Sita LV (2016), The Importance of Titrating Antibodies for Immunocytochemical Methods. Curr Protoc Neurosci 76:2 12 11-12 1237.

Hsu SM, Raine L, Fanger H (1981), Use of avidin-biotin-peroxidase complex (ABC) in immunoperoxidase techniques: a comparison between $A B C$ and unlabeled antibody (PAP) procedures. J Histochem Cytochem 29:577-580.

Hsu SY, Liang SG, Hsueh AJ (1998), Characterization of two LGR genes homologous to gonadotropin and thyrotropin receptors with extracellular leucine-rich repeats and a $G$ protein-coupled, seven-transmembrane region. Mol Endocrinol 12:1830-1845.

Huang SN, Minassian H, More JD (1976), Application of immunofluorescent staining on paraffin sections improved by trypsin digestion. Lab Invest 35:383-390.

Idris F, Muharram SH, Zaini Z, Alonso S, Diah S (2019), Invasion of a murine in vitro bloodbrain barrier co-culture model by dengue virus serotypes 1 to 4 . Arch Virol.

Imam SA, Young L, Chaiwun B, Taylor CR (1995), Comparison of two microwave based antigen-retrieval solutions in unmasking epitopes in formalin-fixed tissue for immunostaining. Anticancer Res 15:1153-1158.

Ji J, Wei X, Wang Y (2014), Embryonic stem cell markers Sox-2 and OCT4 expression and their correlation with WNT signal pathway in cervical squamous cell carcinoma. Int J Clin Exp Pathol 7:2470-2476.

Kalebi AY, Dada MA (2007), Application of immunohistochemistry in clinical practice: a review. East Afr Med J 84:389-397.

Kanthiya K, Khunnarong J, Tangjitgamol S, Puripat N, Tanvanich S (2016), Expression of the p16 and Ki67 in Cervical Squamous Intraepithelial Lesions and Cancer. Asian Pac J Cancer Prev 17:3201-3206. 
Keuker Jl, Rochford CD, Witter MP, Fuchs E (2003), A cytoarchitectonic study of the hippocampal formation of the tree shrew (Tupaia belangeri). J Chem Neuroanat 26:1-15.

Kim JW, Nam SM, Yoo DY, Jung HY, Hwang IK, Seong JK, Yoon YS (2018), Strain-specific differential expression of astrocytes and microglia in the mouse hippocampus. Brain Behav 8:e00961.

Li X, Guo L, Liu Y, Su Y, Xie Y, Du J, Wang S, Wang H, et al. (2018), MicroRNA-21 promotes wound healing via the Smad7-Smad2/3-Elastin pathway. Exp Cell Res 362:245-251.

Libard S, Cerjan D, Alafuzoff I (2019), Characteristics of the tissue section that influence the staining outcome in immunohistochemistry. Histochem Cell Biol 151:91-96.

Lopez J, Ruiz G, Organista-Nava J, Gariglio P, Garcia-Carranca A (2012), Human papillomavirus infections and cancer stem cells of tumors from the uterine cervix. Open Virol J 6:232-240.

Lopez-Chavez A, Miledi R, Martinez-Torres A (2005), Cloning and functional expression of the bovine $\operatorname{GABA}(\mathrm{C})$ rho2 subunit. Molecular evidence of a widespread distribution in the CNS. Neurosci Res 53:421-427.

Low KL, Ma C, Soma KK (2017), Tyramide Signal Amplification Permits Immunohistochemical Analyses of Androgen Receptors in the Rat Prefrontal Cortex. J Histochem Cytochem 65:295-308.

Martinez-Ramirez I, Del-Castillo-Falconi V, Mitre-Aguilar IB, Amador-Molina A, CarrilloGarcia A, Langley E, Zentella-Dehesa A, Soto-Reyes E, et al. (2017), SOX2 as a New Regulator of HPV16 Transcription. Viruses 9.

Matos LL, Trufelli DC, de Matos MG, da Silva Pinhal MA (2010), Immunohistochemistry as an important tool in biomarkers detection and clinical practice. Biomark Insights 5:9-20.

McCluggage WG (2007), Immunohistochemistry as a diagnostic aid in cervical pathology. Pathology 39:97-111.

Miledi R (1967), Spontaneous synaptic potentials and quantal release of transmitter in the stellate ganglion of the squid. J Physiol 192:379-406.

Miledi R (1969), Transmitter action in the giant synapse of the squid. Nature 223:12841286.

Miledi R, Slater CR (1966), The action of calcium on neuronal synapses in the squid. J Physiol 184:473-498.

National epidemiological surveillance system. Unique information system. Ministry of Health M (2018), Cases by State of dysplasia and neoplasm. Epidemiol Bull 26:56.

Nosek BA, Errington TM (2017), Making sense of replications. Elife 6.

Organization WH (2018), Cervical Cancer. World Health Organization.

Palma E, Inghilleri M, Conti L, Deflorio C, Frasca V, Manteca A, Pichiorri F, Roseti C, et al. (2011), Physiological characterization of human muscle acetylcholine receptors from ALS patients. Proc Natl Acad Sci U S A 108:20184-20188.

Prieto D, Aparicio G, Morande PE, Zolessi FR (2014), A fast, low cost, and highly efficient fluorescent DNA labeling method using methyl green. Histochem Cell Biol 142:335-345.

Rensing S (1999), Immobilization and anaesthesia of nonhuman primates. Primate Rep 55:33-38.

Reya T, Morrison SJ, Clarke MF, Weissman IL (2001), Stem cells, cancer, and cancer stem cells. Nature 414:105-111. 
Rodriguez-Callejas JD, Cuervo-Zanatta D, Rosas-Arellano A, Fonta C, Fuchs E, Perez-Cruz C (2019), Loss of ferritin-positive microglia relates to increased iron, RNA oxidation, and dystrophic microglia in the brains of aged male marmosets. Am J Primatol:e22956.

Rodriguez-Callejas JD, Fuchs E, Perez-Cruz C (2016), Evidence of Tau Hyperphosphorylation and Dystrophic Microglia in the Common Marmoset. Front Aging Neurosci 8:315.

Rosas-Arellano A, Ochoa-de la Paz LD, Miledi R, Martinez-Torres A (2007), Brain distribution and molecular cloning of the bovine GABA rho1 receptor. Neurosci Res 57:347-353.

Rosas-Arellano A, Tejeda-Guzman C, Lorca-Ponce E, Palma-Tirado L, Mantellero CA, Rojas P, Missirlis F, Castro MA (2018), Huntington's disease leads to decrease of GABA-A tonic subunits in the D2 neostriatal pathway and their relocalization into the synaptic cleft. Neurobiol Dis 110:142-153.

Rosas-Arellano A, Villalobos-Gonzalez JB, Palma-Tirado L, Beltran FA, Carabez-Trejo A, Missirlis F, Castro MA (2016), A simple solution for antibody signal enhancement in immunofluorescence and triple immunogold assays. Histochem Cell Biol 146:421-430.

Saper CB, Sawchenko PE (2003), Magic peptides, magic antibodies: guidelines for appropriate controls for immunohistochemistry. J Comp Neurol 465:161-163.

Sawa M, Inoue M, Yabuki A, Kohyama M, Miyoshi N, Setoguchi A, Yamato O (2017), Rapid immunocytochemistry for the detection of cytokeratin and vimentin: assessment of its diagnostic value in neoplastic diseases of dogs. Vet Clin Pathol 46:172-178.

Schnell SA, Staines WA, Wessendorf MW (1999), Reduction of lipofuscin-like autofluorescence in fluorescently labeled tissue. J Histochem Cytochem 47:719-730.

Schonbrunn A (2014), Editorial: Antibody can get it right: confronting problems of antibody specificity and irreproducibility. Mol Endocrinol 28:1403-1407.

Shi SR, Key ME, Kalra KL (1991), Antigen retrieval in formalin-fixed, paraffin-embedded tissues: an enhancement method for immunohistochemical staining based on microwave oven heating of tissue sections. J Histochem Cytochem 39:741-748.

Shimada M, Nishimura R, Nogawa T, Hatae M, Takehara K, Yamada H, Kurachi H, Yokoyama Y, et al. (2013), Comparison of the outcome between cervical adenocarcinoma and squamous cell carcinoma patients with adjuvant radiotherapy following radical surgery: SGSG/TGCU Intergroup Surveillance. Mol Clin Oncol 1:780-784.

Sternberger LA, Sternberger NH (1986), The unlabeled antibody method: comparison of peroxidase-antiperoxidase with avidin-biotin complex by a new method of quantification. J Histochem Cytochem 34:599-605.

Streefkerk JG, van der Ploeg M, Kors N (1975), Some aspects of immunohistoperoxidase reactions in the agarose bead model system. Ann N Y Acad Sci 254:212-222.

Stuhmer W (1992), Electrophysiological recording from Xenopus oocytes. Methods Enzymol 207:319-339.

Sun B, Ye X, Li Y, Zhang W (2015), Lgr5 is a potential prognostic marker in patients with cervical carcinoma. Int J Clin Exp Pathol 8:1783-1789.

Taatjes DJ, Roth J (2017), In focus in HCB. Histochem Cell Biol 148:575-576.

Voskuil JL (2017), The challenges with the validation of research antibodies. F1000Res 6:161. 
Waldvogel HJ, Curtis MA, Baer K, Rees MI, Faull RL (2006), Immunohistochemical staining of post-mortem adult human brain sections. Nat Protoc 1:2719-2732.

Zaglia T, Di Bona A, Chioato T, Basso C, Ausoni S, Mongillo M (2016), Optimized protocol for immunostaining of experimental GFP-expressing and human hearts. Histochem Cell Biol 146:407-419.

Zheng ZX, Sun Y, Bu ZD, Zhang LH, Li ZY, Wu AW, Wu XJ, Wang XH, et al. (2013), Intestinal stem cell marker LGR5 expression during gastric carcinogenesis. World J Gastroenterol 19:8714-8721. 
Figure 1. Single and triple label immunohistofluorescence using SIP and ASE protocol in marmoset hippocampus. Localization of GFAP-positive cells in hippocampal region in common marmoset (non-human primate) and tree shrew (Scandentia species). Representative photomicrographs showing the GFAP signal in A) the common marmoset and B) the tree shrew using the SIP (left panels) and the ASE protocol (right panels), followed by the quantification of total astrocyte number per field and of the fluorescence intensity of the GFAP processes. The mean data and standard deviation are plotted for both methods. Asterisks represent statistically significant differences $(\mathrm{p}<0.05)$. Astrocytes detected by the ASE protocol not only showed more distinguishable processes, but also displayed higher fluorescence intensity compared to astrocytes detected by means of the SIP. C) A representative GFAP-positive cells ASE was found with twice than SIP quantifiable processes located in hippocampus of common marmoset is shown under higher magnification. D) The SIP protocol was used to detect the iron storage protein ferritin (blue), and the phospho-tau AT100 (red) in parallel with the ASE protocol for detection of GFAP (green in left and right panels). GFAP signal was observed near and into the pyramidal layer (pl) and adjacent to the granular layer (gl) of the hippocampal region. DAPI was used as a nuclear counterstain.

Figure 2. Immunocytofluorescence against Claudin 2 and 4 in MDCK monolayers under EGF treatment. A) Representative photomicrographs comparing the BSA (left) and ASE (right) methods revealed the classical distribution of Claudin 4 in membranes (arrowheads) as well as in the intracellular space (arrows). The ASE image shows remarkable stain in the usual localization of Claudin 4, plotted following signal quantification (fluorescence intensity and area) in the right panel. B) Immunolocalization for Claudin 2 (left panels) and Claudin 4 (right panels) without EGF treatment (upper panels) or following incubation with EGF (lower panels) resulting in diminishing expression of Claudin 2 and increased expression of Claudin 4 (densitometric analysis of the fluorescence intensity and area are represented in the graphs on the right panels). Asterisks represent statistically significant differences ( $p$ $<0.05)$.

Figure 3. Improved immunohistochemistry for cervical cancer biomarkers Ki67, Sox-2 and Lgr-5 on biopsies from three patients following ASE addition to standard protocols. A) Cervical paraffin embedded sections showing a subset of Ki67 positive cells are in brown (arrows) and hematoxylin nuclear counterstaining in blue. Primary antibody solution was conducted using the commercial ImmunoDetector Protein Blocker / Antibody Diluent (Bio SB), and using Rabbit HRP Polymer Detection (Cat. No. M3R531) for secondary antibody. The primary antibody was incubated using ASE protocol, whereas Mouse/Rabbit inmunoDetector DAB HRP Brown was chosen for secondary antibody, no arrows indicating brown signal are presented in these panels due to obvious location of Ki-67 signal (right panel). B) 
Cervical sections showing SOX-2 positive cells in brown under commercial diluent protocol (arrows in left panels), and with ASE protocol (right panel). C) Cytoplasmatic-membrane detection of cervical cancer biomarker Lgr-5 by immunohistochemistry on cervical cancer paraffin embedded tissues for commercial diluent and ASE. The intensity of brown areas was quantified following the corresponding normalization against background. The mean value and standard deviations from three samples per patient from at least two separate experiments are plotted at the right side of each image. Statistical significance was considered when p<0.05. Abbreviations: P1, P2, P3 mean patients 1, 2 and 3; CD, commercial diluent.

Figure. 4. Representative controls of the immunolabeling for cancer biomarkers. A). The tissues incubated omitting primary antibodies with commercial ImmunoDetector Protein Blocker / Antibody Diluent (Bio SB) (left panel) or with ASE solution (right panel). B). Isotype control. ChromPure Rabbit IgG (left panel) and ChromPure Mouse IgG (right panel) both diluted in ASE showing no signal. Secondary antibody Rabbit HRP Polymer Detection or Mouse/Rabbit inmunoDetector was with DAB HRP Brown. Magnification: 40X. 
Figure 1

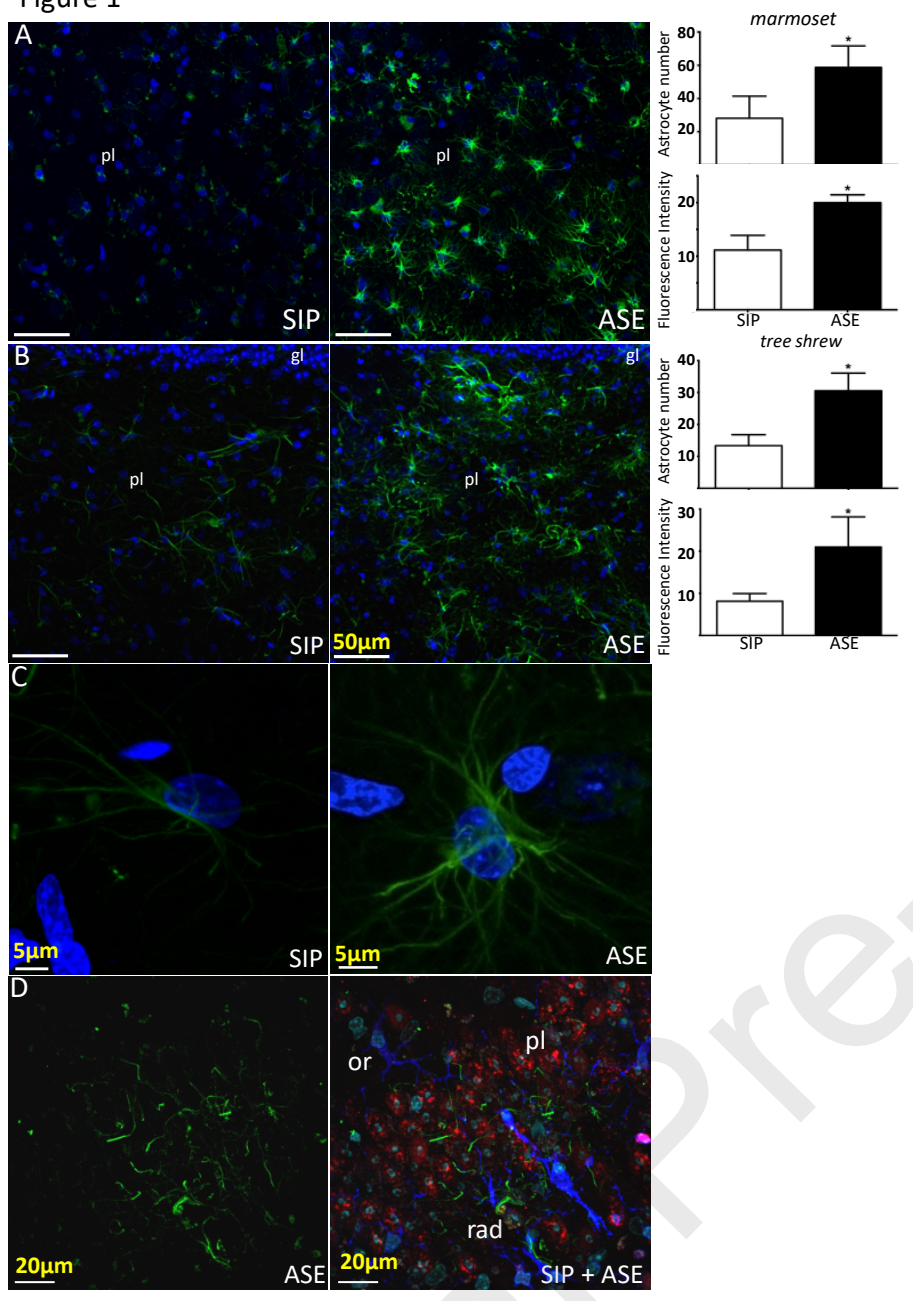


Figure 2
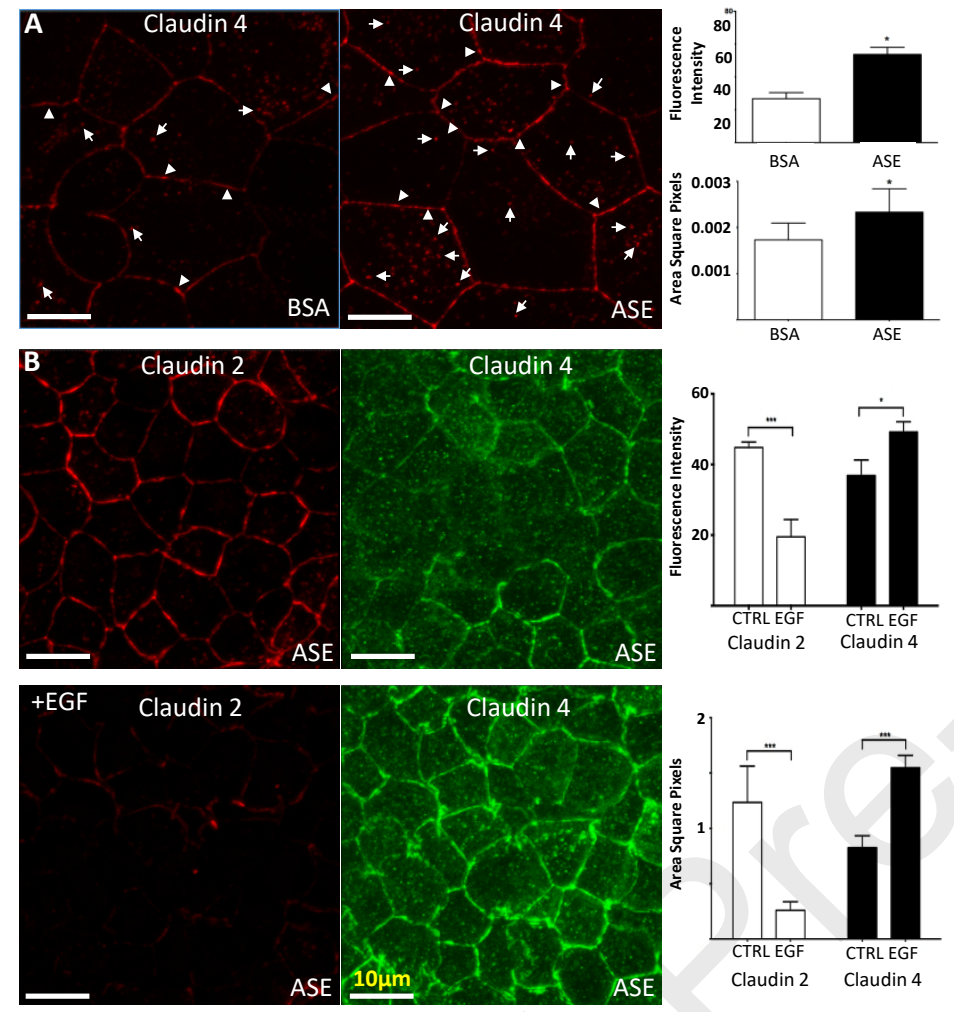
Figure 3

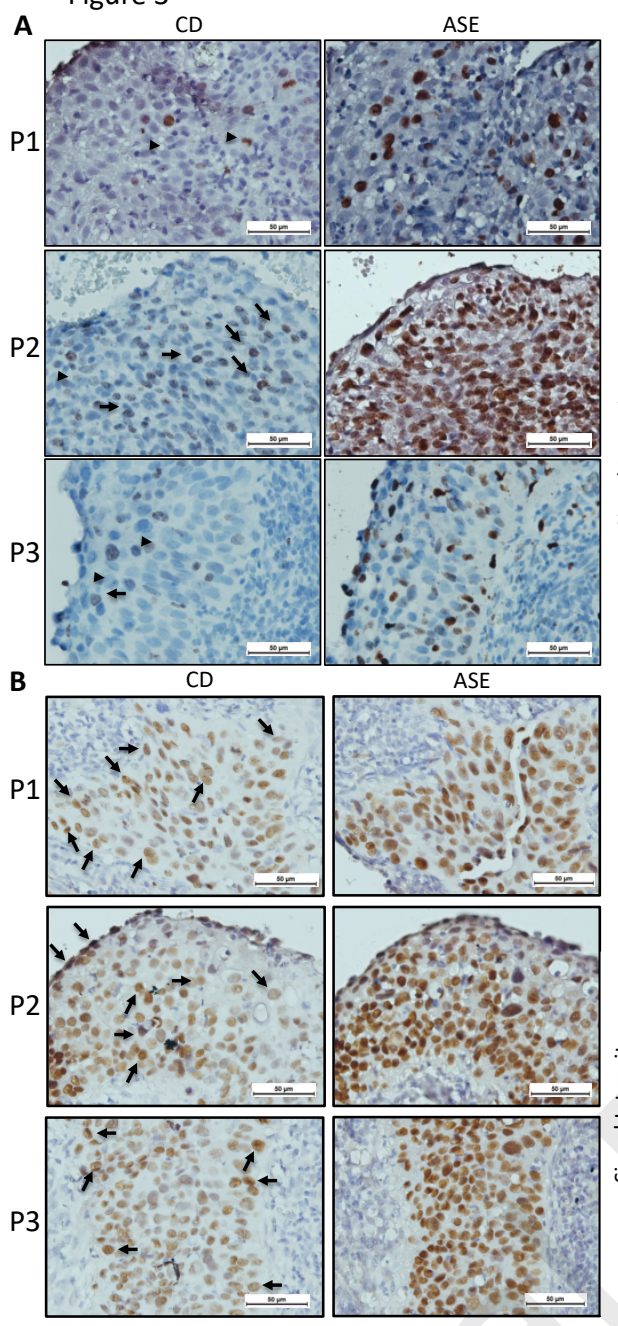

Ki-67 immunoreactivity

in squamous carcinoma

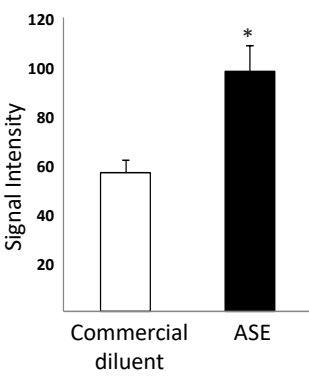

Sox-2 immunoreactivity in squamous carcinoma

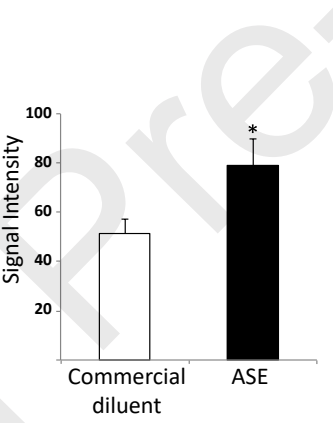




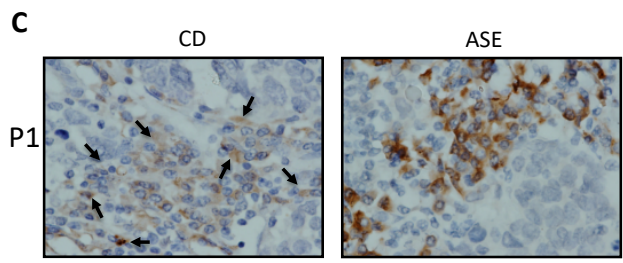

Lgr-5 immunoreactivity

in squamus carcinoma
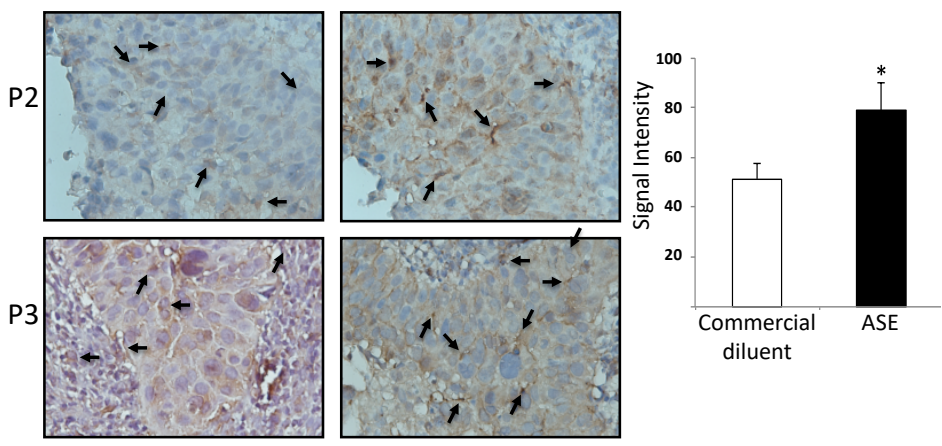
Figure 4

A

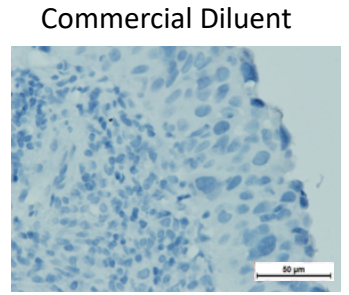

Rabbit IgG

B
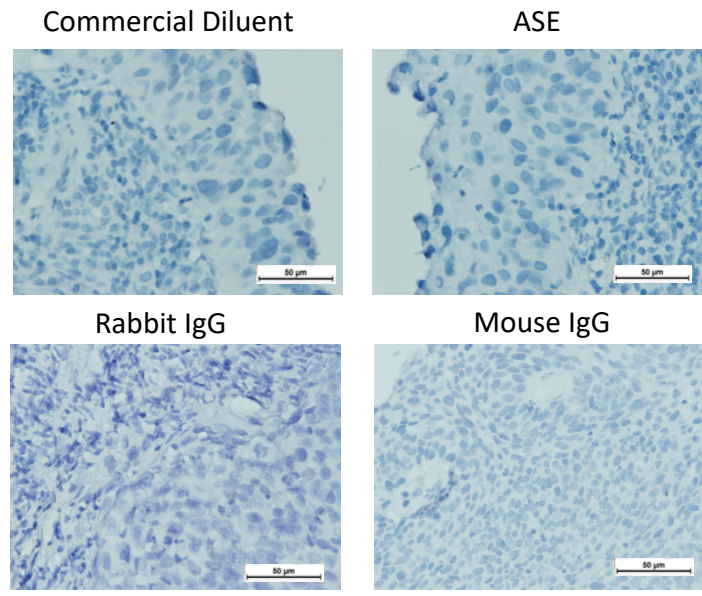

Mouse IgG

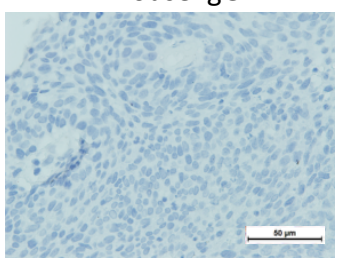




\begin{tabular}{|c|c|c|}
\hline & $\begin{array}{l}\text { INNMUNOSTAIN } \\
\text { COMMERCIAL }\end{array}$ & $\begin{array}{c}\text { INNMUNOSTAIN } \\
\text { ASE }\end{array}$ \\
\hline $\begin{array}{l}\text { Retriever } \\
\text { Citrate }\end{array}$ & $\begin{array}{l}\text { ImmunoDNA Retriever } \\
\text { 20X with Citrate }\end{array}$ & $\begin{array}{l}\text { ImmunoDNA Retriever } \\
\text { 20X with Citrate }\end{array}$ \\
\hline $\begin{array}{l}\text { Peroxidase } \\
\text { Blocker }\end{array}$ & $\begin{array}{l}\text { PolyDetector Peroxidase } \\
\text { Blocker ( Bio SB) }\end{array}$ & $\begin{array}{l}\text { PolyDetector Peroxidase } \\
\text { Blocker ( Bio SB) }\end{array}$ \\
\hline $\begin{array}{l}\text { Protein } \\
\text { blocker }\end{array}$ & $\begin{array}{l}\text { ImmunoDetector } \\
\text { Protein Blocker / } \\
\text { Antibody Diluent } \\
\text { ( Bio SB) }\end{array}$ & $\begin{array}{l}\text { Solution Blocker } \\
(2 \% \text { Bovine fetal } \\
\text { serum, } 50 \mathrm{mM} \text { glycine, } \\
0.05 \% \text { Tween } 20,0.1 \% \\
\text { Triton } \\
\text { X-100 and } 0.1 \% \text { BSA } \\
\text { diluted in PBS) }\end{array}$ \\
\hline $\begin{array}{l}\text { Solution } \\
\text { Primary } \\
\text { antibody } \\
\text { incubation }\end{array}$ & $\begin{array}{l}\text { ImmunoDetector } \\
\text { Protein Blocker / } \\
\text { Antibody Diluent } \\
\text { ( Bio SB) }\end{array}$ & $\begin{array}{l}\text { Antibody signal } \\
\text { Enhancer ASE } \\
(10 \mathrm{mM} \text { glycine, } 0.05 \% \\
\text { Tween } 20,0.1 \% \text { Triton } \\
\text { X-100 and } 0.1 \% \\
\text { hydrogen peroxide in } \\
\text { PBS) }\end{array}$ \\
\hline $\begin{array}{l}\text { Primary } \\
\text { antibody }\end{array}$ & $\begin{array}{l}\text { Anti-Ki67 antibody } \\
\text { [SP6] (ab16667) } \\
\text { Anti-LGR5 antibody } \\
\text { (ab75732) } \\
\text { Anti-Sox-2 (A-5) } \\
\text { antibody, (sc-365964) }\end{array}$ & $\begin{array}{l}\text { Anti-Ki67 antibody } \\
\text { [SP6] (ab16667) } \\
\text { Anti-LGR5 antibody } \\
\text { (ab75732) } \\
\text { Anti-Sox-2 (A-5) } \\
\text { antibody, (sc-365964) }\end{array}$ \\
\hline $\begin{array}{l}\text { Secondary } \\
\text { antibody }\end{array}$ & $\begin{array}{l}\text { MACH } 3 \text { Rabbit HRP } \\
\text { Polymer Detection } \\
\text { (M3R531) }\end{array}$ & $\begin{array}{l}\text { Mouse/Rabbit Immuno } \\
\text { Detector DAB HRP } \\
\text { Brown (\# BSB 0001) }\end{array}$ \\
\hline
\end{tabular}


- ASE showing significant increase of immunofluorescence in brain primate tissue

- ASE is effective as antibody enhancer in immunocytofluorescence in cell culture.

- ASE treatment showed no changes in location and/or distribution of immunolabeling

- As a highlighted ASE increased intensity of immunolocalization in cancer biomarkers

- ASE exhibit very low cost against clinical protocols which use commercial enhancers 